\title{
Expression of soluble programmed death-1 protein in peripheral blood regulatory $T$ cells and its effects on rheumatoid arthritis progression
}

\author{
CHUN-FENG REN ${ }^{1 *}$, YA-XIN ZHAO $^{2 *}$, CHUN-FENG HOU $^{1}$, LUAN LUAN $^{3}$, \\ GUO-QING DUAN ${ }^{3}$, SHU-JIE LI ${ }^{1}$ and JIAN-HONG ZHAO ${ }^{1}$ \\ Departments of ${ }^{1}$ Rheumatism and ${ }^{2}$ Pharmaceutical, The First People's Hospital of Jining; \\ ${ }^{3}$ Department of Joint Surgery, The Affiliated Hospital of Jining Medical College, Jining, Shandong 272000, P.R. China
}

Received October 19, 2015; Accepted September 21, 2016

DOI: $10.3892 / \mathrm{mmr} .2016 .5968$

\begin{abstract}
The present study aimed to investigate the role of the soluble programmed death-1 (sPD-1) protein, which is released by peripheral blood regulatory $\mathrm{T}$ cells (Treg) during the progression of rheumatoid arthritis (RA). From October 2012 to May 2014, 82 RA patients (RA group) and 90 healthy volunteers (healthy controls; HC) were recruited. Cluster of differentiation (CD)4, CD25 and forkhead/winged helix transcription factor $\mathrm{p} 3$ (Foxp3) and expression of cytotoxic $\mathrm{T}$ lymphocyte associated antigen 4 (CTLA-4) and Foxp3 were detected by flow cytometry. Expression of sPD-1 in Treg was detected by western blot analysis. Immunosuppressive activity of $\mathrm{CD} 4^{+} \mathrm{CD} 25^{-}$Treg was measured via thiazolyl blue in an MTT assay. ELISA was used to detect interleukin-10 (IL-10), transforming growth factor beta (TGF- $\beta$ ), interleukin-4 (IL-4), interferon- $\gamma($ IFN- $\gamma$ ) and nuclear factor of activated $\mathrm{T}$ cells (NF-AT). It was observed that in peripheral blood, $\mathrm{CD} 4{ }^{+} \mathrm{CD} 25-\mathrm{FOXP}^{+} / \mathrm{CD}^{+}{ }^{+}$levels were reduced in the $\mathrm{RA}$ group $(\mathrm{P}<0.001)$, and sPD-1 levels were markedly higher $(\mathrm{P}<0.001)$, compared with the $\mathrm{HC}$ group. Additionally, it was observed that relative SPD-1 protein expression in the small interfering RNA (siRNA)-sPD-1 treated group was reduced compared with the untreated and scrambled siRNA groups (all $\mathrm{P}<0.0001$ ). The mean fluorescence intensity of CTLA-4 and Foxp3 decreased markedly upon transfection with siRNA-sPD-1 ( $\mathrm{P}<0.001)$. Compared with the normal $\mathrm{CD} 4^{+} \mathrm{CD} 25^{-} \mathrm{T}$ group, optical density $(\mathrm{OD})_{540}$ values, IFN- $\gamma / \mathrm{IL}-4$ concentration ratio and
\end{abstract}

Correspondence to: Ms. Chun-Feng Hou, Department of Rheumatism, The First People's Hospital of Jining, 6 Health Road, Jining, Shandong 272000, P.R. China

E-mail: cf_hou2015@163.com

*Contributed equally

Key words: soluble programmed death-1, rheumatoid arthritis, regulatory $\mathrm{T}$ cells, peripheral blood, immunosuppressive activity, nuclear factor of activated $\mathrm{T}$ cells activity
NF-AT activity in siRNA untreated and scramble groups reduced significantly (all $\mathrm{P}<0.001$ ). $\mathrm{OD}_{540}$ value, IFN- $\gamma / \mathrm{IL}-4$ concentration ratio and NF-AT activity in the siRNA-sPD-1 group were significantly upregulated (all $\mathrm{P}<0.001$ ). Therefore, sPD-1 may suppress the level of $\mathrm{CD} 4^{+} \mathrm{CD} 25^{-}$Tregs in the peripheral blood of RA patients, and may be involved in a variety of immune processes mediated by $\mathrm{CD} 4^{+} \mathrm{CD} 25^{-}$Tregs.

\section{Introduction}

Rheumatoid arthritis (RA), an inflammatory disorder of the joints, is characterized by chronic synovitis, progressive erosions and cartilage destruction, resulting in deformed and painful joints and loss of joint function (1). RA affects $0.5-1 \%$ of adults worldwide with 5-50 out of every 100,000 people diagnosed with the condition annually, and it also has a greater incidence in females and elderly populations (2). If untreated, RA may result in joint damage, disability and a reduced quality of life, and additionally cardiovascular diseases and other comorbidities $(3,4)$. The exact etiology of the condition remains to be elucidated; however, certain studies suggest that RA is associated with the overproduction of proinflammatory cytokines, that prevent the maintenance of immunological homeostasis, and that the cytokine milieu is responsible for the persistent immunological responses that are central to the pathogenesis of RA $(5,6)$. In addition, an imbalance between the adaptive and innate immune systems often contributes to the excessive immune responses observed in RA (7). As a result, activation and recruitment of immune cells into the joints, particularly lymphocytes and monocytes, are characteristic of RA (8).

Regulatory $\mathrm{T}$ cells (Treg) are a lymphocyte subpopulation that is important in cell-mediated immunity (9). The activation of Tregs is mediated by underlying mechanisms involving central and peripheral lymphoid organs (10). Soluble programmed death-1 (sPD-1), an immunoregulatory molecule member of the immunoglobulin superfamily expressed in Tregs, is important in downregulating the immune system (11). sPD-1 is a $55-\mathrm{kDa}$ transmembrane protein with $24 \%$ amino acid homology to cytotoxic T-lymphocyte antigen 4 (CTLA-4) (6). Recent studies have suggested that SPD-1 may be key to disease activity in human RA $(5,12)$. Consistent with this, a 
previous study observed that SPD-1 expression levels are high in synovial Tregs and macrophages from RA patients (13). Although the role of sPD-1 in Tregs in patients with RA has been extensively studied, the underlying mechanisms and its implications for RA remain to be elucidated (14). In the current study, sPD-1 expression levels were investigated in peripheral blood Tregs from RA patients and healthy controls and the effect of SPD-1 in RA progression was assessed by alteration of its expression in Tregs, via the use of small interfering RNA (siRNA).

\section{Materials and methods}

Patients. The present study was conducted between October 2012 and May 2014 on a population of RA patients $(n=82)$ admitted to the Pharmaceutical Department, The First People's Hospital of Jining (Jining, China). Patients recruited to the study were carefully evaluated to confirm they met the specific diagnostic criteria required for RA (15). The study subjects consisted of 35 female and 47 male RA patients, with a mean age of $55 \pm 2.5$ years and a disease duration range of 4-20 months. The patients had been recently diagnosed with the condition or had not undergone treatment with corticosteroids or immunosuppressive therapy within the previous year. Patients suffering from other autoimmune diseases, malignant tumors, acute or chronic pathogen infection or who had a history of allergies were excluded. Within the study period, a total of 90 healthy volunteers, 48 males and 42 females, with a mean age of $53 \pm 3.5$ years, were enrolled as the healthy control (HC) group. Subjects with other autoimmune diseases, a history of allergies or recent history of infectious disease were excluded from the HC group. The RA group and the HC group demonstrated no statistically significant differences in age or gender. Following approval by the ethics committee of The First People's Hospital of Jining, written informed consent was obtained from each subject; the study conformed to the Declaration of Helsinki (16).

Collection of blood samples. Following an overnight fast of 10-12 h, a volume of $10 \mathrm{ml}$ of venous blood was obtained from all subjects. EDTA $(5 \mathrm{ml})$ served as an anticoagulant, and blood samples were stored at $-70^{\circ} \mathrm{C}$ until further use.

Extraction of peripheral blood mononuclear cells (PBMCs). Peripheral venous blood $(2 \mathrm{ml})$ was collected in vials containing EDTA, and was diluted with an equal volume of PBS. The diluted blood was carefully layered onto $2 \mathrm{ml}$ Ficoll solution (density, 1.007; pH, 6.5-7.5; Ficoll separation solution:diluted blood, 1:2 ratio; Shanghai No. 2 Reagent Factory, Shanghai, China), ensuring that the interphase was not disturbed. Following centrifugation in a swing bucket rotor at $626 \mathrm{x} g$ at room temperature for $20 \mathrm{~min}$, the mixture separated into three layers, and a milky turbid cell layer was obtained at the Ficoll-blood interphase. The cell layer was carefully withdrawn using a Pasteur pipette, transferred into a new centrifuge tube, diluted 1:5 with PBS and centrifuged at in a swing bucket rotor $352 \mathrm{x} g$ at room temperature for $5 \mathrm{~min}$. The supernatant was discarded and the PBS wash was repeated once. The isolated PBMCs were resuspended in PBS, and the cell concentration was adjusted to $1 \times 10^{6} / \mathrm{ml}$.
Fluorescence staining and flow cytometry. The prepared PBMC suspension was vortexed, and $100 \mathrm{ml}$ was added into flow tubes. A mixture containing $100 \mathrm{ml}$ fluorescein isothiocyanate (FITC)-conjugated anti-cluster of differentiation (CD) 4 (cat. no. 11-0040-81) and $20 \mathrm{ml}$ phycoerythrin (PE)-conjugated anti-CD25 antibodies (cat. no. 12-0390-80; both from Shanghai Xin Le Bio Technology Co., Ltd., Shanghai, China) was added into each tube and incubated in the dark at $4^{\circ} \mathrm{C}$ for $30 \mathrm{~min}$. The mixture was washed once using $2 \mathrm{ml}$ flow cytometry staining buffer (Guangzhou Sagene Biotech Co., Ltd., Guangzhou, China) or cold PBS, and centrifuged in a swing bucket rotor at $352 \mathrm{x} g$ at room temperature for $5 \mathrm{~min}$. The supernatant was discarded and $20 \mathrm{ml}$ rat anti-human forkhead box protein 3 (FOXP3; clone, PCH101) antibody (cat. no. 12-4776-42; Shanghai Xin Le Bio Technology Co., Ltd.) was added, and to the HC group $20 \mathrm{ml}$ IgG2a isotype negative control antibody (cat. no. 12-4321-83; Shanghai Xin Le Bio Technology Co., Ltd.) was added. The incubation was performed in fresh membrane rupture buffer (Shanghai Yes Service Biotech, Inc., Shanghai, China) in the dark at $4^{\circ} \mathrm{C}$ for $30 \mathrm{~min}$. The samples were washed with $2 \mathrm{ml}$ membrane permeabilization buffer (Shanghai Yes Service Biotech, Inc.) twice and resuspended in $500 \mathrm{ml}$ flow cytometry staining buffer. A total of 1,000 cells were acquired from each sample on a flow cy tometer and the results were analyzed with CXP software version 10.0.7 (Beckman Coulter, Inc., CA, USA). The percentage of $\mathrm{CD}^{+}{ }^{+} \mathrm{CD} 25^{-} \mathrm{FOXP}^{+}$cells present within the total $\mathrm{CD}^{+}$population was calculated.

Isolation and purification of Tregs. PBMCs from the study subjects, obtained by Ficoll density gradient separation, were used for the positive selection of human $\mathrm{CD} 4^{+} \mathrm{CD} 25^{-}$Tregs with the Easy Sep Human $\mathrm{CD}^{+} \mathrm{T}$ cell Enrichment kit (Stemcell Technologies, Inc., Vancouver, BC, Canada). PBS containing 2\% fetal calf serum (FCS; Shanghai Yes Service Biotech, Inc.) and $1 \mathrm{~mol} / \mathrm{l}$ EDTA was used as isolation and purification buffer. The cell concentration was adjusted to $1 \times 10^{8} / \mathrm{ml}$ with isolation and purification buffer, and $\sim 2 \times 10^{8}$ cells were added per tube. An antibody cocktail $(10 \mu \mathrm{l} / \mathrm{ml})$ was added into polystyrene tubes and incubated at room temperature for $15 \mathrm{~min}$. Magnetic beads $(5 \mu \mathrm{l} / \mathrm{ml})$ were added into the tubes, mixed and incubated at room temperature for $10 \mathrm{~min}$. The polystyrene tubes were vortexed, and inserted into a magnet and incubated at room temperature for $5 \mathrm{~min}$. The solution in the tube was discarded, carefully retaining the magnetic beads. The solution volume was adjusted to $2.5 \mathrm{ml}$ with buffer, mixed to wash the beads, inserted into the magnet again and incubated at room temperature for $5 \mathrm{~min}$. PBS ( $3 \mathrm{ml}$ ) was added into the polystyrene tubes and centrifuged in a swing bucket rotor at 1,500 $\mathrm{x} g$, at room temperature for 5 min. Following removal of the supernatant, purified cells were obtained and an aliquot of the cells was stained with anti-CD4-FITC and anti-CD25-PE. The purity was determined as $>90 \%$ via flow cytometry.

Transfection of siRNA-sPD-1. PBMCs from RA patients were divided into two groups: One group was seeded in a 96-well culture plate containing complete medium with $5 \times 10^{3} \mathrm{CD}^{+} \mathrm{CD} 25^{-}$Tregs $(90 \mu \mathrm{l})$ per well. The second group was seeded in a 96-well culture plate following mixing 
with enhanced virus reagent (Engreen Biosystem Co., Ltd., Auckland, New Zealand) with $5 \times 10^{3} \mathrm{CD}^{+} \mathrm{CD} 25^{-}$Tregs (90 $\mu \mathrm{l})$ per well. Four transfection groups, with three different concentration gradients of multiplicity of infection (MOI) in each group were set up. To estimate the optimal MOI, siRNA (5'-GATATTTGCTGTCTTTATA-3') and lentiviral vectors with meaningless sequences (Shanghai Genechem Co., Ltd., Shanghai, China) at three different concentrations $\left(1 \times 10^{8}, 1 \times 10^{7}\right.$ and $\left.1 \times 10^{6} \mathrm{TU} / \mathrm{ml}\right)$ were prepared and added into corresponding wells. Diluted polybrene solution (Shanghai Yeasen Biotechnology Co. Ltd. Shanghai, China) was added. Following continuous culture for $12 \mathrm{~h}$, fresh medium was added and fluorescence expression was observed four days following infection. The MOI of 10 led to a highly efficient infection in $\mathrm{CD} 4^{+} \mathrm{CD} 25^{-}$Tregs. Based on this result, an MOI of 10 was used for siRNA expression experiments. Accordingly, $4 \times 10^{6}$ cells were inoculated in a culture flask in RPMI 1640 culture medium (Shanghai Yes Service Biotech, Inc.) containing 10\% FCS and incubated at $37^{\circ} \mathrm{C}, 5 \% \mathrm{CO}_{2}$. Cells were divided into 3 groups: i) Untreated $\mathrm{CD} 4^{+} \mathrm{CD} 25^{-}$Tregs (untreated group), ii) $\mathrm{CD}^{+}{ }^{+} \mathrm{CD} 25^{-}$Tregs expressing siRNA-sPD-1 (siRNA-sPD-1 group) and iii) $\mathrm{CD} 4{ }^{+} \mathrm{CD} 25^{-}$Tregs expressing meaningless sequence (scramble group). The cells were infected at MOI 10 for a total of $72 \mathrm{~h}$. Cells were collected for protein quantification by western blotting, and the remainder were stored at $-20^{\circ} \mathrm{C}$ until further use.

Western blotting to determine SPD-1 protein expression levels following transfection. Total protein was extracted using a Total Protein Extraction kit (cat. no. LS1030; Promega Corporation, Madison, WI, USA) according to the manufacturer's protocol. The proteins were blotted sodium dodecyl sulfate polyacrylamide gel electrophoresis (SDS-PAGE), the concentration of separation gel was $15 \%$ and the concentration of spacer gel was $5 \%$. Next, the proteins were transferred to nitrocellulose filter (NC filter) with the condition of $150 \mathrm{~mA}$ at $4^{\circ} \mathrm{C}$ for $3 \mathrm{~h}$. The filter membrane was placed into a mouse anti-GST mAb antibody (cat. no. 136700; 1:1,000; Shanghai Xin Le Bio Technology Co., Ltd.) which was diluted by $2 \%$ skim milk powder (prepared by TBS Tween-20). The filter membrane was then incubated with horseradish peroxidase-goat anti-mouse IgG (cat. no 400002-500; 1:1,000; Shanghai Xin Le Bio Technology Co.,Ltd.) was used for testing. Enhancedchemiluminescence (ECL), using an EasyBlot ECL kit (cat. no. 36222ES60; Shanghai Yeasen Biotechnology Co., Ltd.) was used for developing, and the reaction was terminated when the target band had clear staining. Bicinchoninic acid (BCA) method was used to prepare standard protein solution, and $\beta$-actin was regarded as internal reference with the molecular weight of $43 \mathrm{kD}$. Quantity One software version 4.31 (Bio-Rad Laboratories, Inc., Hercules, CA, USA) was used to detect the ratio of the protein expressions of western blot and the grey value of internal reference band and was used to quantify the total protein (17).

Flow cytometry for CTLA-4 and FOXP3 expression. Cells $\left(1 \times 10^{5} /\right.$ well $)$ from the untreated, siRNA-sPD-1 and scramble groups were seeded onto a 96-well plate coated with $1 \mu \mathrm{g} / \mathrm{ml}$ anti-CD3 (cat. no. 04-460; Shanghai Xin Le Bio Technology Co., Ltd.) and $1 \mu \mathrm{g} / \mathrm{ml}$ anti-CD28 (cat. no. 13-0281-81;
Shanghai Xin Le Bio Technology Co., Ltd.) and adjusted to a final volume of $200 \mu \mathrm{l}$ per well with RPMI 1640 containing $10 \% \mathrm{FCS}$. The cells were cultured in a $37^{\circ} \mathrm{C}, 5 \% \mathrm{CO}_{2}$ incubator and collected after $24 \mathrm{~h}$. Cells were washed with precooled PBS, resuspended in $100 \mu \mathrm{l}$ PBS, and anti-rat CD152-FITC (cat. no. 359-020)/CTLA-4-FITC (cat. no. 1790-02; Shanghai Xin Le Bio Technology Co., Ltd.) antibodies were added, and incubated at $4^{\circ} \mathrm{C}$ in the dark for $30 \mathrm{~min}$. Cells were washed once with precooled PBS, resuspended in $1 \mathrm{ml}$ fixed/penetration working solution (Shanghai Xin Le Bio Technology Co., Ltd.) per $10^{6}$ cells, and incubated at $4^{\circ} \mathrm{C}$ in the dark for $2 \mathrm{~h}$. Subsequently, cells were washed twice with $2 \mathrm{ml} 1 \mathrm{X}$ membrane rupture buffer, resuspended in PBS and detected by flow cytometry. FITC-IgG (1:1,000, cat. no. 5267919001) and FITC-IgG2 $\alpha$ (1:1,000, cat. no. 1079-02 ) isotype control antibodies (Shanghai Yes Service Biotech, Inc.) served as negative controls.

Thiazolyl blue (MTT) assay. $\mathrm{CD} 4{ }^{+} \mathrm{CD} 25^{-}$Tregs were co-cultured with $\mathrm{CD} 4^{+} \mathrm{CD} 25^{-} \mathrm{T}$ cells at 1:1. The $\mathrm{CD} 4^{+} \mathrm{CD} 25^{-} \mathrm{T}$ cells were set as a blank control group. All cells were cultured with RPMI 1640 containing 10\% FCS. Cells were seeded in a 96-well culture plate at $1 \times 10^{5}$ cells (final volume, $200 \mu \mathrm{l}$ ) per well. Cells were activated by $1 \mu \mathrm{g} / \mathrm{ml}$ anti-CD3 and $1 \mu \mathrm{g} / \mathrm{ml}$ anti-CD28 coated onto the 96 -well plate. The remaining wells in the 96-well plate were filled with $200 \mu \mathrm{l}$ sterile PBS. MTT absorptiometry (Shanghai Xin Le Bio Technology Co., Ltd.; cat. no. M6494) was performed. After $24 \mathrm{~h}$ of incubation, the cells were washed with PBS, and $20 \mu \mathrm{l}$ MTT solution $(5 \mathrm{mg} / \mathrm{ml})$ was added to the cells. After another $24 \mathrm{~h}$ of incubation, the supernatant was absorbed, and then added with $150 \mu \mathrm{l}$ dimethyl sulfoxide (Shanghai Yes Service Biotech, Inc.; cat. no. WAK-DMSO-70), and the optical density (OD) values, at a wavelength of $540 \mathrm{~nm}$, were examined by KHB-ST-360 type microplate reader (Shanghai Kehua Bio-Engineering Co., Ltd., Shanghai, China) the following day.

Enzyme-linked immunosorbent assay (ELISA). Cells from the untreated, siRNA-sPD-1 and scramble groups were seeded in 96-well plates coated with $1 \mu \mathrm{g} / \mathrm{ml}$ anti-CD3 (cat.no.05121-25-5; Shanghai Yes Service Biotech, Inc.) and $1 \mu \mathrm{g} / \mathrm{ml}$ anti-CD28 (cat. no. 10311-25-500; Shanghai Yes Service Biotech, Inc.), and incubated in a $37^{\circ} \mathrm{C}, 5 \% \mathrm{CO}_{2}$ incubator. After $24 \mathrm{~h}$, the supernatant from each group was collected and stored at $-80^{\circ} \mathrm{C}$ for detection of interleukin (IL)-10, transforming growth factor- $\beta$ TGF- $\beta$ ), IL-4 and interferon- $\gamma($ IFN- $\gamma$ ) levels. Cells obtained from the three groups were used to detect the activity of nuclear factor of activated T cells (NFAT) with nucleoprotein extracted using the NE-PER nuclear and cytoplasmic extract kit (cat. no. 78833; Shanghai Maibio Biotech Co., Ltd, Shanghai, China) and detected by luminex ELISA test kit (cat. no. 40-50016; Luminex Corporation, Shanghai, China) according to the manufacturer's protocol. OD values at a wavelength of $450 \mathrm{~nm}$ were recorded.

Statistical analysis. Statistical analysis was conducted using SPSS software version 20.0 (IBM SPSS, Armonk, NY, USA). Data are presented as the mean \pm standard deviation. The data of each group were normally distributed. The comparison of independent samples between two groups was conducted using a unpaired Student's $t$-test, and comparison 
A

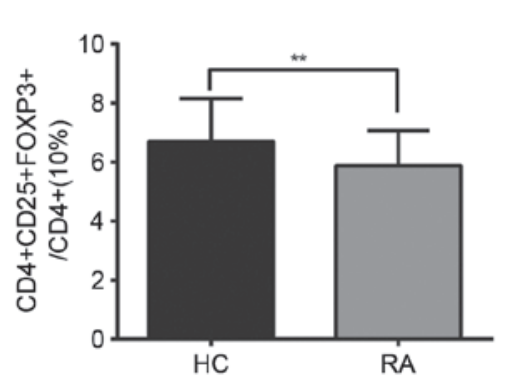

B

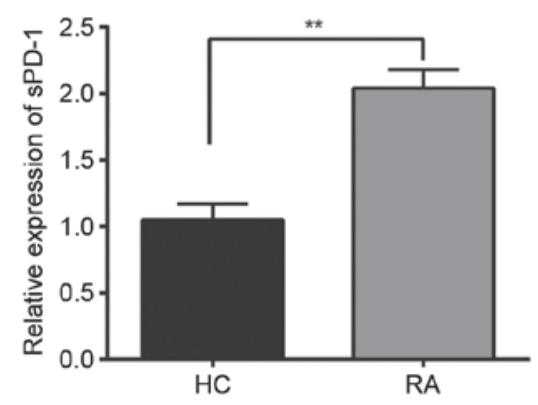

C

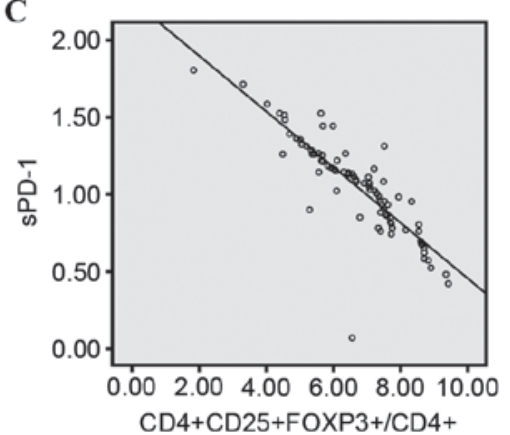

Figure 1. Peripheral blood CD4, CD25, FOXP3 and sPD-1 expression in RA patients and HC. (A) $\mathrm{CD}^{+}{ }^{-\mathrm{CD}} 25^{-} \mathrm{FOXP} 3^{+}$cells in peripheral blood, as a $\%$ of total CD4 ${ }^{+}$cells. (B) sPD-1 expression in peripheral blood. (C) Scatter plot revealing the expression levels of CD4, CD25, and FOXP3, and sPD-1 are negatively correlated. ${ }^{* *} \mathrm{P}<0.001$ compared with the RA and the HC group. CD, cluster of differentiation; FOXP3, forkhead/winged helix transcription factor p3; sPD-1, soluble programmed death-1; RA, rheumatoid arthritis; $\mathrm{HC}$, healthy control.

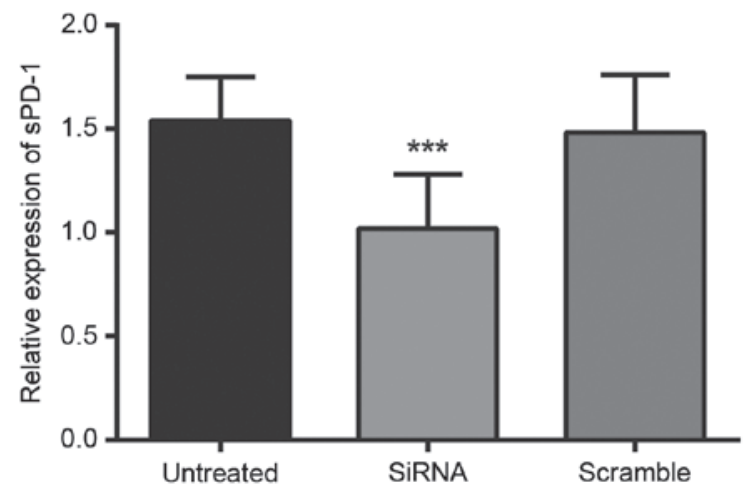

Figure 2. Protein expression levels of sPD-1 within Tregs in untreated, siRNA-sPD-1 and scramble groups, as detected by western blot analysis. The expression levels of sPD-1 in the siRNA-sPD-1 group were significantly reduced compared with the untreated and scramble groups. Untreated group, CD $4^{+} \mathrm{CD} 25^{-}$Tregs; siRNA-sPD-1 group, CD4 ${ }^{+} \mathrm{CD} 25^{-}$Tregs transfected with siRNA-sPD-1; scramble group, $\mathrm{CD}^{+} \mathrm{CD} 25^{-}$Tregs transfected with meaningless sequence. ${ }^{* * *} \mathrm{P}<0.0001$ vs. untreated and scramble groups. sPD-1, soluble programmed death-1; Treg, peripheral blood regulatory T cells; siRNA, small interfering RNA; CD, cluster of differentiation.

of data among multiple groups was performed using one-way analysis of variance. The least significant difference test was used in the pairwise comparison. Pearson correlation analysis was performed for the correlation between SPD-1 and $\mathrm{CD} 4^{+} \mathrm{CD} 25{ }^{-} \mathrm{FOXP}^{+} / \mathrm{CD} 4^{+} . \mathrm{P}<0.05$ was considered to indicate a statistically significant difference.

\section{Results}

Peripheral blood CD4, CD25, FOXP3 and SPD-1 expression. The percentage of peripheral blood $\mathrm{CD} 4^{+} \mathrm{CD} 25^{-} \mathrm{FOXP}^{+}$cells of the total $\mathrm{CD}^{+}$population in the RA group was significantly reduced compared with the HC group (5.87 $\pm 1.20 \mathrm{vs}$. $6.70 \pm 1.45 \%$; $\mathrm{P}<0.001$; Fig. $1 \mathrm{~A})$. The RA group had significantly greater sPD-1 levels compared with the HC group $(2.04 \pm 0.14$ vs. $1.05 \pm 0.12$; $\mathrm{P}<0.001$; Fig. $1 \mathrm{~B})$. The expression of sPD-1 was negatively correlated with $\mathrm{CD} 4{ }^{+} \mathrm{CD} 25^{-} \mathrm{FOXP} 3^{+} / \mathrm{CD}^{+}{ }^{+}$cells ( $r=-0.855$; $<<0.001$; Fig. 1C).

Protein expression levels of SPD-1 in Tregs following transfection. The protein expression levels of sPD-1 in Tregs were detected by western blotting, as presented in Fig. 2. The protein expression levels of SPD-1 within Tregs in the untreated, siRNA-sPD-1 and scramble groups were $1.54 \pm 0.16$, $1.02 \pm 0.11$ and $1.51 \pm 0.18$, respectively. The protein expression levels of sPD-1 in the siRNA-sPD-1 group (1.02 \pm 0.11$)$ were significantly reduced compared with the untreated $(1.54 \pm 0.16)$ and scramble $(1.51 \pm 0.18)$ groups $(\mathrm{P}<0.0001)$. No differences in SPD-1 protein expression levels were observed between the untreated and scramble groups $(\mathrm{P}>0.05)$.

Effect of SPD-1 siRNA on CTLA-4 and FOXP3 expression. The expression of the transcription factors CTLA-4 and FOXP3 in Tregs was detected by flow cytometry (Table I). A total of $24 \mathrm{~h}$ following combined stimulation with anti-CD3/CD28, the mean fluorescence intensity of CTLA-4 and FOXP3 in the siRNA-sPD-1 group was significantly reduced compared with untreated and scramble groups (all $\mathrm{P}<0.001$ ). The results indicated that $\mathrm{SPD}-1$ expression in $\mathrm{CD} 4^{+} \mathrm{CD} 25^{-}$Treg increased the expression of CTLA-4 and FOXP3.

Effect of $S P D-1$ on the immunosuppressive activity of $C D 4^{+} C D 25^{-}$Tregs. MTT results demonstrated that, under anti-CD3/CD28 activation, compared with the normal $\mathrm{CD} 4{ }^{+} \mathrm{CD} 25^{-} \mathrm{T}$ group, $\mathrm{OD}_{540}$ values in the untreated and scramble groups reduced significantly $(0.48 \pm 0.01,0.35 \pm 0.04$ and $0.34 \pm 0.03$, respectively; all $\mathrm{P}<0.001)$. Following the silencing of sPD-1 in CD $4{ }^{+} \mathrm{CD} 25^{-}$Tregs with siRNA, the $\mathrm{OD}_{540}$ value in the siRNA-sPD-1 group was upregulated in comparison with the untreated and scramble groups $(0.51 \pm 0.15 ; \mathrm{P}<0.001)$. Therefore, $\mathrm{CD} 4^{+} \mathrm{CD} 25^{-}$Tregs inhibited the proliferation of effector $\mathrm{T}$ cells; however, the immunosuppressive activity of $\mathrm{CD} 4^{+} \mathrm{CD} 25^{-}$Tregs was weakened by siRNA-mediated silencing of sPD-1 (Table II).

IL-10 and TGF- $\beta$ levels, as assessed by ELISA. IL-10 and TGF- $\beta$ levels in the $\mathrm{CD} 4^{+} \mathrm{CD} 25^{-}$Treg supernatant were detected via ELISA (Fig. 3). ELISA results indicated that $24 \mathrm{~h}$ following stimulation with anti-CD3/CD28, IL-10 levels in the untreated, siRNA-sPD-1 and scramble groups were 9.86 $\pm 0.87,6.12 \pm 0.58$ and $9.75 \pm 0.85 \mathrm{pg} / \mathrm{ml}$, respectively, whereas TGF- $\beta$ levels in the untreated, siRNA-sPD-1 and scramble groups were 68.24 \pm 9.54 , $32.75 \pm 6.23$ and $67.10 \pm 9.10 \mathrm{pg} / \mathrm{ml}$, respectively. IL-10 and TGF- $\beta$ 
A

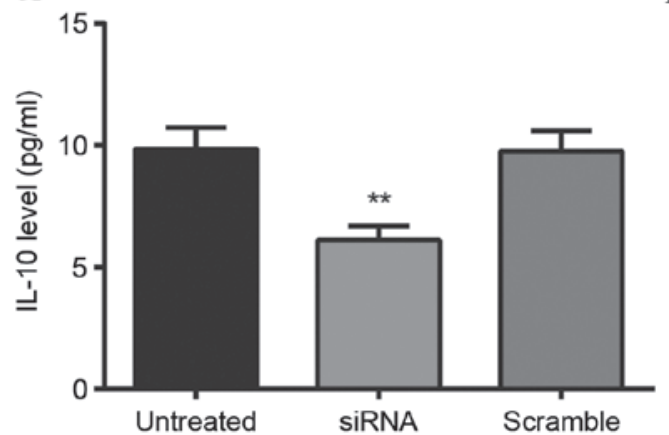

B

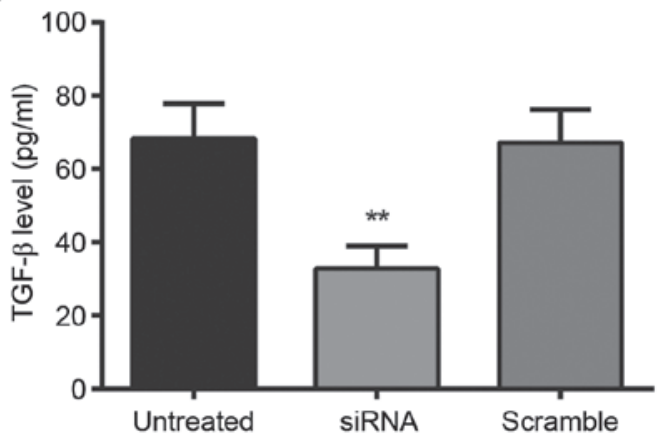

Figure 3. Effect of sPD-1 expression on the level of cell factors. (A) IL-10 and (B) TGF- $\beta$ levels in the CD4 ${ }^{+} \mathrm{CD} 25^{-}$Treg supernatant of untreated, siRNA-sPD- 1 and scramble groups were detected by ELISA. IL-10 and TGF- $\beta$ expression levels in the siRNA-sPD-1 group were significantly reduced compared with the untreated and scramble groups. Untreated group, CD4+CD25- Tregs; siRNA-sPD-1 group, CD4+CD25- Tregs transfected with siRNA-sPD-1; scramble group, CD4+CD25- Tregs transfected with meaningless sequence. ${ }^{* *} \mathrm{P}<0.001$ vs. untreated and scramble groups. sPD-1, soluble programmed death-1; IL-10, interleukin-10; TGF- $\beta$, transforming growth factor $\beta ; \mathrm{CD}$, cluster of differentiation; Treg, regulatory T cells; siRNA, small interfering RNA.

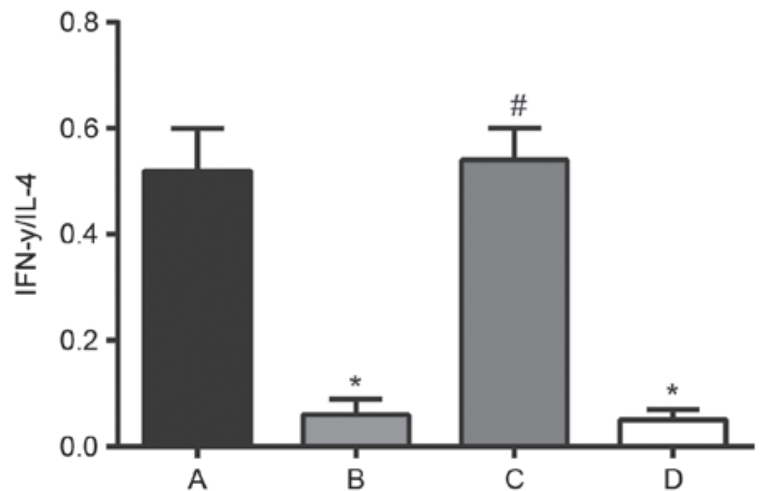

Figure 4. Effect of sPD-1 on IFN- $\gamma / \mathrm{IL}-4$ concentration ratio and $\mathrm{CD} 4{ }^{+} \mathrm{CD} 25$ Treg-mediated Th2 polarization in the Treg/CD4+CD25- T effector co-culture supernatant, as detected by ELISA. A, normal CD4+CD25T cell; B, untreated; C, siRNA-sPD-1; and D, scramble groups. Compared with the normal CD4+CD25- T cell group, the IFN- $\gamma / \mathrm{IL}-4$ concentration ratio in the co-culture supernatant in the untreated and scramble groups reduced significantly. Following siRNA silencing of sPD-1 in CD4+CD25Tregs, the IFN- $\gamma / \mathrm{IL}-4$ concentration ratio was upregulated compared with the untreated group. Untreated group, CD4+CD25- Tregs; siRNA-sPD-1 group, CD4+CD25- Tregs transfected with siRNA-sPD-1; scramble group, CD4+CD25- Tregs transfected with meaningless sequence. "P<0.001 vs. normal CD4+CD25- T group; ${ }^{\#} \mathrm{P}<0.001$ vs. untreated group. sPD-1, soluble programmed death-1; IFN- $\gamma$, interferon- $\gamma$; IL-4, interleukin-4; CD cluster of differentiation; Treg, regulatory $\mathrm{T}$ cells; Th, T helper; siRNA, small interfering RNAs.

levels in the $\mathrm{CD} 4{ }^{+} \mathrm{CD} 25^{-}$Treg supernatant in the siRNA-sPD-1 group were therefore reduced compared with the untreated and scramble groups $(\mathrm{P}<0.001)$, indicating that $\mathrm{SPD}-1$ expression in $\mathrm{CD} 4^{+} \mathrm{CD} 25^{-}$Treg influences the production of IL-10 and TGF- $\beta$.

Effect of $S P D-1$ on the IFN- $\gamma / I L-4$ concentration ratio. IFN- $\gamma$ and IL-4 levels in the CD $4^{+} \mathrm{CD} 25^{-} \mathrm{Treg} / \mathrm{CD} 4^{+} \mathrm{CD} 25$ $\mathrm{T}$ effector co-culture supernatant were detected via ELISA (Fig. 4). Compared with the normal $\mathrm{CD} 4{ }^{+} \mathrm{CD} 25^{-} \mathrm{T}$ group, the IFN- $\gamma / \mathrm{IL}-4$ concentration ratio in the co-culture supernatant from the untreated $(0.52 \pm 0.08$ vs. $0.06 \pm 0.03 ; \mathrm{P}<0.001)$ and scramble groups $(0.52 \pm 0.08$ vs. $0.05 \pm 0.02 ; \mathrm{P}<0.001)$ reduced significantly. The IFN- $\gamma / \mathrm{IL}-4$ concentration ratio in the siRNA-sPD-1 group was upregulated compared with the untreated group $(0.54 \pm 0.06$ vs. $0.06 \pm 0.02 ; \mathrm{P}<0.001)$,

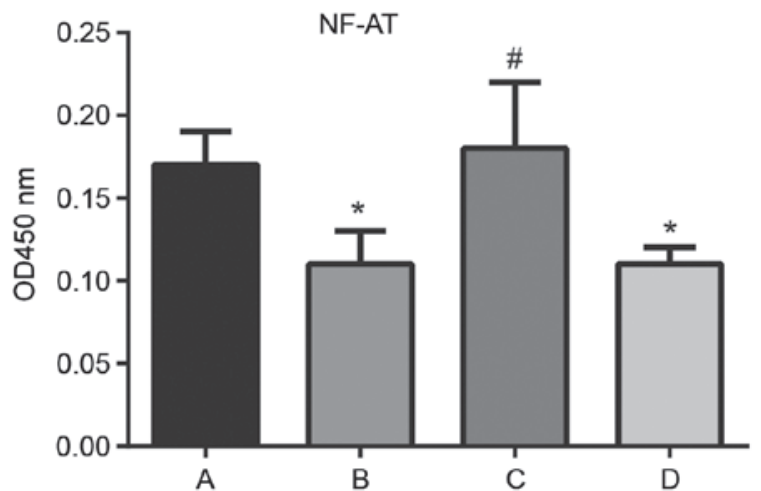

Figure 5. Effect of $\mathrm{SPD}-1$ on the activity of NF-AT in $\mathrm{T}$ cells in the Treg/CD $4^{+} \mathrm{CD} 25^{-} \mathrm{T}$ effector co-culture supernatant. The activity of NF-AT in normal CD4+CD25- T cells, and untreated, siRNA-sPD-1 and scramble groups was detected by ELISA. A, normal CD4+CD25- T cell; B, untreated; C, siRNA-sPD-1; and D, scramble groups. NF-AT activity decreased in untreated and scramble groups; however, significantly increased in the siRNA-sPD-1 group compared with the untreated and scramble groups. Untreated group, CD4+CD25- Tregs; siRNA-sPD-1 group, CD4+CD25Tregs transfected with siRNA-sPD-1; scramble group, CD4+CD25- Tregs transfected with meaningless sequence. " $\mathrm{P}<0.001$ vs. normal CD4+CD25$\mathrm{T}$ cell group; ${ }^{*} \mathrm{P}<0.001$ vs. untreated group. $\mathrm{sPD}-1$, soluble programmed death-1; NF-AT, nuclear factor of activated T cells; Treg, regulatory T cells; $\mathrm{CD}$, cluster of differentiation; siRNA, small interfering RNA.

suggesting a weakened polarization of $\mathrm{T}$ cells towards the $\mathrm{T}$ helper (Th)2 phenotype, and an enhanced polarization of $\mathrm{T}$ cells towards the Th1 phenotype. Therefore, downregulation of sPD- 1 expression in $\mathrm{CD} 4^{+} \mathrm{CD} 25^{-}$Tregs increased the IFN- $\gamma /$ IL-4 concentration ratio, indicating that SPD-1 may be involved in $\mathrm{CD} 4^{+} \mathrm{CD} 25^{-}$Treg-mediated Th2 polarization.

Effect of SPD-1 on NF-AT activity in T cells. The activity of NF-AT in T cells in the $\mathrm{CD} 4^{+} \mathrm{CD} 25^{-} \mathrm{Treg} / \mathrm{CD} 4^{+} \mathrm{CD} 25^{-} \mathrm{T}$ effector co-culture supernatant was detected via ELISA (Fig. 5). In comparison with the normal $\mathrm{CD} 4^{+} \mathrm{CD} 25^{-} \mathrm{T}$ group, NF-AT activity decreased in the untreated $(0.17 \pm 0.02$ vs. $0.11 \pm 0.02$; $\mathrm{P}<0.001)$ and scramble groups $(0.17 \pm 0.02$ vs. $0.11 \pm 0.01$; $\mathrm{P}<0.001$ ), whereas NF-AT activity increased significantly in the siRNA-sPD-1 group compared with the untreated group $(0.18 \pm 0.04$ vs. $0.11 \pm 0.02 ; \mathrm{P}<0.001)$, suggesting that $\mathrm{sPD}-1$ 
Table I. Comparison of transcription factor CTLA-4 and FOXP3 expression in $\mathrm{CD}^{+} \mathrm{CD} 25^{-}$Tregs between untreated, siRNA-sPD-1 and scramble groups.

\begin{tabular}{llcc}
\hline & \multicolumn{3}{c}{ Group } \\
\cline { 2 - 4 } Marker & Untreated & siRNA-sPD-1 & Scramble \\
\hline CTLA-4 & $81.06 \pm 4.54^{\mathrm{a}}$ & $32.75 \pm 4.53$ & $79.59 \pm 5.58^{\mathrm{a}}$ \\
FOXP3 & $58.36 \pm 2.45^{\mathrm{a}}$ & $27.24 \pm 1.87$ & $57.85 \pm 2.26^{\mathrm{a}}$ \\
\hline
\end{tabular}

Flow cytometry was performed to detect CTLA-4 and FOXP3 mean fluorescence intensity. Data are expressed as the mean \pm standard deviation. Untreated group, $\mathrm{CD} 4{ }^{+} \mathrm{CD} 25^{-}$Tregs; siRNA-sPD-1 group, $\mathrm{CD} 4^{+} \mathrm{CD} 25^{-}$Tregs transfected with siRNA-sPD-1; scramble group, $\mathrm{CD} 4^{+} \mathrm{CD} 25^{-}$Tregs transfected with meaningless sequence. ${ }^{\mathrm{a}} \mathrm{P}<0.05$ vs. siRNA-sPD-1 group. CTLA-4, cytotoxic T lymphocyte associated antigen; FOXP3, forkhead/winged helix transcription factor $\mathrm{p} 3$; $\mathrm{CD}$, cluster of differentiation; Treg, regulatory T cells; sPD-1, soluble programmed death-1; siRNA, small interfering RNA.

Table II. Effect of sPD-1 on $\mathrm{CD}^{+} \mathrm{CD} 25^{-}$Treg-mediated immunosuppression of effector $\mathrm{T}$ cells.

\begin{tabular}{lc}
\hline Group & $\mathrm{OD}_{540} \mathrm{~nm}$ value \\
\hline Normal CD4 ${ }^{+} \mathrm{CD} 25^{-} \mathrm{T}$ & $0.49 \pm 0.04$ \\
Untreated & $0.35 \pm 0.04^{\mathrm{a}}$ \\
siRNA-sPD-1 & $0.48 \pm 0.05^{\mathrm{b}}$ \\
Scramble & $0.34 \pm 0.03^{\mathrm{a}}$ \\
\hline
\end{tabular}

MTT assays were performed to evaluate absorptiometry (OD) values at a wavelength of $540 \mathrm{~nm}$. Data are expressed as the mean \pm standard deviation. Untreated group, $\mathrm{CD} 4^{+} \mathrm{CD} 25^{-}$Tregs; siRNA-sPD-1 group, $\mathrm{CD} 4^{+} \mathrm{CD} 25^{-}$Tregs transfected with siRNA-sPD-1; scramble group, $\mathrm{CD} 4^{+} \mathrm{CD} 25^{-}$Tregs transfected with meaningless sequence. ${ }^{a} \mathrm{P}<0.001$ vs. normal $\mathrm{CD} 4^{+} \mathrm{CD} 25^{-} \mathrm{T}$ group; ${ }^{\mathrm{b}} \mathrm{P}<0.001$ vs. untreated and scramble groups. sPD-1, soluble programmed death-1; CD, cluster of differentiation; Treg, regulatory $\mathrm{T}$ cells; $\mathrm{OD}_{540} \mathrm{~nm}$ value, absorptiometry value at $540 \mathrm{~nm}$, siRNA, small interfering RNA.

expression reduced the activity of NF-AT in $\mathrm{CD} 4^{+} \mathrm{CD} 25^{-} \mathrm{T}$ cells. Thus, sPD-1 may affect $\mathrm{CD} 4^{+} \mathrm{CD} 25^{-}$Treg-mediated suppression of NF-AT activity in effector T cells, influencing their immunosuppressive function.

\section{Discussion}

Previous studies support a key role for Tregs in RA pathogenesis, and the involvement of the SPD-1 signaling pathway in peripheral tolerance by inhibition of Tregs at the level of synovial tissue $(5,18,19)$. In humans, a role for sPD-1 in the regulation of immunologic self-tolerance and autoimmunity was suggested by the observed associations between $P D-1$ gene polymorphisms and autoimmune diseases, including systemic lupus erythematosus, RA, type 1 diabetes mellitus, and multiple sclerosis $(13,20,21)$. The present study aimed to investigate the role of SPD-1 in RA and to identify the function of sPD-1 in Tregs from RA patients.
The present study investigated the expression of sPD-1 in RA patients and identified that SPD-1 expression was significantly increased in peripheral blood $\mathrm{CD} 4^{+} \mathrm{CD} 25^{-}$Tregs in RA patients, indicating that sPD-1 may be involved in the regulation of Treg effector function at the site of inflammation. Furthermore, the data revealed that following siRNA-mediated silencing of sPD- 1 expression in $\mathrm{CD}^{+} \mathrm{CD} 25^{-}$Tregs, the proliferation of Tregs was significantly inhibited following siRNA transfection and the immunosuppressive activity of $\mathrm{CD} 4^{+} \mathrm{CD} 25^{-}$Tregs was weakened, suggesting that sPD-1 promotes the immunosuppressive activity of Tregs. sPD-1, as a co-signaling molecule and a co-inhibitor, is involved in directing, modulating and fine-tuning Treg receptor signals, leading to suppression of Treg activation (22). Spatio-temporal expression of sPD-1 may negatively control the priming, growth, differentiation and functional maturation of a Treg response (23). In RA patients, sPD-1 was upregulated in Tregs, and these Tregs may become 'exhausted', with progressive loss of effector function and proliferative capacity, resulting in decreased proliferation, cytokine production, cytolytic activity and a reduction in viral load (13). The important role of sPD-1 in downregulating the immune system is accomplished by preventing the activation of Tregs, which in turn reduces autoimmunity and promotes self-tolerance associated with the increased risk of RA (6). A recent study by Greisen et al (5) revealed that increased SPD-1 expression may be associated with early RA disease activity and radiographic progression, suggesting an important role of sPD-1 in mediating inflammatory as well as radiographic disease progression.

In addition, the present study observed that following silencing of sPD- 1 in $\mathrm{CD}^{+} \mathrm{CD} 25^{-}$Tregs with siRNA, the expression levels of CTLA-4, Foxp3, IL-10 and TGF- $\beta$ all decreased, whereas the activity of NF-AT increased, implying that SPD-1 expression may regulate Treg responses through influencing the expression levels of CTLA-4, FOXP3, IL-10 and TGF- $\beta$, as well as NF-AT activity. A previous study by Fife et al (24) reported that SPD-1 and CTLA-4 inhibit T cells in RA through different mechanisms, and CTLA- 4 acts by recruiting protein phosphatase 2 . A previous study demonstrated that FOXP3, a member of the forkhead/winged-helix family of transcriptional regulators, is important in distinguishing Tregs from recently activated, non-regulatory $\mathrm{CD} 4^{+} \mathrm{CD} 25^{-} \mathrm{T}$ cells and is a specific marker of $\mathrm{CD} 4^{+} \mathrm{CD} 25^{-}$ Tregs (25). Jiao et al (26) reported an accumulation of FOXP3-expressing Tregs in RA, and this recruitment may be dependent on the distinct chemokine receptors expressed on Tregs. Heo et al (19) demonstrated that overexpressed IL-10 is detected in autoimmune disease patients and that it may be useful in the treatment of autoimmune diseases. In addition, TGF- $\beta$ may be involved in ingress of inflammatory cells into the rheumatoid joint, which is associated with the pathogenesis of RA (27). Checker et al (28) indicated that potent anti-inflammatory activity in RA is mediated via suppression of NF-AT activity, which is consistent with the results of the present study.

In conclusion, the results of the present study demonstrated that SPD-1 is upregulated in $\mathrm{CD} 4^{+} \mathrm{CD} 25^{-}$Tregs isolated from the PBMCs of RA patients. The immunosuppressive activity of $\mathrm{CD} 4^{+} \mathrm{CD} 25^{-}$Tregs was weakened following sPD-1 
silencing, the expression levels of CTLA-4, FOXP3, IL-10 and TGF- $\beta$ decreased and the IFN- $\gamma / \mathrm{IL}-4$ concentration ratio and the activity of NF-AT increased. The data from the present study suggested a potential novel mechanism underlying the pathogenesis of RA and may subsequently provide a novel target for its treatment.

\section{References}

1. Wang $\mathrm{CH}$, Yao H, Chen LN, Jia JF, Wang L, Dai JY, Zheng ZH, Chen ZN and Zhu P: CD147 induces angiogenesis through a vascular endothelial growth factor and hypoxia-inducible transcription factor $1 \alpha$-mediated pathway in rheumatoid arthritis. Arthritis Rheum 64: 1818-1827, 2012.

2. Scott DL, Wolfe F and Huizinga TW: Rheumatoid arthritis. Lancet 376: 1094-1108, 2010.

3. Kingsley G, Scott IC and Scott DL: Quality of life and the outcome of established rheumatoid arthritis. Best Pract Res Clin Rheumatol 25: 585-606, 2011.

4. Kerola AM, Kauppi MJ, Nieminen T, Rantalaiho V, Kautiainen H, Kerola T, Virta LJ, Pohjolainen T and Puolakka K: Psychiatric and cardiovascular comorbidities as causes of long-term work disability among individuals with recent-onset rheumatoid arthritis. Scand J Rheumatol 44: 87-92, 2015.

5. Greisen SR, Rasmussen TK, Stengaard-Pedersen K, Hetland ML, Hørslev-Petersen K, Hvid M and Deleuran B: Increased soluble programmed death-1 (sPD-1) is associated with disease activity and radiographic progression in early rheumatoid arthritis. Scand J Rheumatol 43: 101-108, 2014.

6. Li S, Liao W, Chen M, Shan S, Song Y, Zhang S, Song H and Yuan Z: Expression of programmed death-1 (PD-1) on CD4+ and CD8+ T cells in rheumatoid arthritis. Inflammation 37: 116-121, 2014.

7. Lin YT, Wang CT, Gershwin ME and Chiang BL: The pathogenesis of oligoarticular/polyarticular vs systemic juvenile idiopathic arthritis. Autoimmun Rev 10: 482-489, 2011.

8. Coffey G, DeGuzman F, Inagaki M, Pak Y, Delaney SM, Ives D, Betz A, Jia ZJ, Pandey A, Baker D, et al: Specific inhibition of spleen tyrosine kinase suppresses leukocyte immune function and inflammation in animal models of rheumatoid arthritis. J Pharmacol Exp Ther 340: 350-359, 2012.

9. Porter DL, Levine BL, Kalos M, Bagg A and June CH: Chimeric antigen receptor-modified $\mathrm{T}$ cells in chronic lymphoid leukemia. N Engl J Med 365: 725-733, 2011.

10. Arpaia N, Campbell C, Fan X, Dikiy S, van der Veeken J, deRoos P, Liu H, Cross JR, Pfeffer K, Coffer PJ and Rudensky AY: Metabolites produced by commensal bacteria promote peripheral regulatory T-cell generation. Nature 504: 451-455, 2013.

11. Haile ST, Dalal SP, Clements V, Tamada K and Ostrand-Rosenberg S: Soluble CD80 restores T cell activation and overcomes tumor cell programmed death ligand 1-mediated immune suppression. J Immunol 191: 2829-2836, 2013.

12. Ceeraz S, Hall C, Choy EH, Spencer J and Corrigall VM: Defective CD8+CD28+ regulatory T cell suppressor function in rheumatoid arthritis is restored by tumour necrosis factor inhibitor therapy. Clin Exp Immunol 174: 18-26, 2013.

13. Dai S, Jia R, Zhang X, Fang Q and Huang L: The PD-1/PD-Ls pathway and autoimmune diseases. Cell Immunol 290: 72-79, 2014.
14. Bertsias GK, Nakou M, Choulaki C, Raptopoulou A, Papadimitraki E, Goulielmos G, Kritikos H, Sidiropoulos P, Tzardi M, Kardassis D, et al: Genetic, immunologic, and immunohistochemical analysis of the programmed death 1 /programmed death ligand 1 pathway in human systemic lupus erythematosus. Arthritis Rheum 60: 207-218, 2009.

15. Kay J and Upchurch KS: ACR/EULAR 2010 rheumatoid arthritis classification criteria. Rheumatology (Oxford) 51: (Suppl 6) vi5-9, 2012

16. M PN: World medical association publishes the revised declaration of Helsinki. Natl Med J India 27: 56, 2014.

17. Kralj JG, Munson MS and Ross D: Total protein quantitation using the bicinchoninic acid assay and gradient elution moving boundary electrophoresis. Electrophoresis 35: 1887-1892, 2014.

18. Boissier MC, Assier E, Biton J, Denys A, Falgarone G and Bessis N: Regulatory T cells (Treg) in rheumatoid arthritis. Joint Bone Spine 76: 10-14, 2009.

19. Heo YJ, Joo YB, Oh HJ, Park MK, Heo YM, Cho ML, Kwok SK, Ju JH, Park KS, Cho SG, et al: IL-10 suppresses Th17 cells and promotes regulatory $\mathrm{T}$ cells in the CD4+ T cell population of rheumatoid arthritis patients. Immunol Lett 127: 150-156, 2010.

20. Woo SR, Turnis ME, Goldberg MV, Bankoti J, Selby M, Nirschl CJ, Bettini ML, Gravano DM, Vogel P, Liu CL, et al: Immune inhibitory molecules LAG-3 and PD-1 synergistically regulate T-cell function to promote tumoral immune escape. Cancer Res 72: 917-927, 2012.

21. Pedoeem A, Azoulay-Alfaguter I, Strazza M, Silverman GJ and Mor A: Programmed death-1 pathway in cancer and autoimmunity. Clin Immunol 153: 145-152, 2014

22. Curran MA, Montalvo W, Yagita H and Allison JP: PD-1 and CTLA-4 combination blockade expands infiltrating T cells and reduces regulatory $\mathrm{T}$ and myeloid cells within B16 melanoma tumors. Proc Natl Acad Sci USA 107: 4275-4280, 2010.

23. Pen JJ, Keersmaecker BD, Heirman C, Corthals J, Liechtenstein T, Escors D, Thielemans K and Breckpot K: Interference with PD-L1/PD-1 co-stimulation during antigen presentation enhances the multifunctionality of antigen-specific T cells. Gene Ther 21: 262-271, 2014.

24. Fife BT, Pauken KE, Eagar TN, Obu T, Wu J, Tang Q, Azuma M, Krummel MF and Bluestone JA: Interactions between PD-1 and PD-L1 promote tolerance by blocking the TCR-induced stop signal. Nat Immunol 10: 1185-1192, 2009.

25. Shen LS, Wang J, Shen DF, Yuan XL, Dong P, Li MX, Xue J, Zhang FM, Ge HL and Xu D: CD4(+)CD25(+)CD127(low/-) regulatory $\mathrm{T}$ cells express Foxp3 and suppress effector $\mathrm{T}$ cell proliferation and contribute to gastric cancers progression. Clin Immunol 131: 109-118, 2009.

26. Jiao Z, Wang W, Jia R, Li J, You H, Chen L and Wang Y: Accumulation of FoxP3-expressing CD4+CD25+ T cells with distinct chemokine receptors in synovial fluid of patients with active rheumatoid arthritis. Scand J Rheumatol 36: 428-433, 2007.

27. Rico MC, Rough JJ, Del Carpio-Cano FE, Kunapuli SP and DeLa Cadena RA: The axis of thrombospondin-1, transforming growth factor beta and connective tissue growth factor: An emerging therapeutic target in rheumatoid arthritis. Curr Vasc Pharmacol 8: 338-343, 2010.

28. Checker R, Sandur SK, Sharma D, Patwardhan RS, Jayakumar S, Kohli V, Sethi G, Aggarwal BB and Sainis KB: Potent anti-inflammatory activity of ursolic acid, a triterpenoid antioxidant, is mediated through suppression of NF- $\mathrm{BB}, \mathrm{AP}-1$ and NF-AT. PloS One 7: e31318, 2012. 